\title{
Transmission Use of System Charges under Future GB Power System Scenarios
}

\author{
Graham W. Ault, Member, IEEE, Ian M. Elders and Richard J. Green
}

\begin{abstract}
If transmission charges are to reflect costs, they should be affected by the location of demand and generation. This paper describes the Investment Cost Related Pricing (ICRP) methodology used to calculate transmission charges in Great Britain (GB), which is based on the marginal investment cost of additional demand or generation, using a DC Load Flow transport model. We apply this existing method to calculate charges for the Supergen FutureNet scenarios for 2020. This study highlights the sensitivities in charges for use of the transmission system arising from plausible demand and generation developments. The changes in tariffs will present financial challenges for system users in some areas. The objective of the work presented is to illustrate the sensitivity of the charges produced by this methodology to changes in demand, generation and network topology rather than compare alternative pricing approaches. The conclusion drawn is that the ICRP system pricing method may be suitable in future years but only with some important issues investigated and resolved.
\end{abstract}

Index Terms - Power system economics, Power transmission economics, Power transmission.

\section{INTRODUCTION}

$\mathrm{T}$ he pricing of electricity transmission is a controversial

subject. There may be broad agreement that a good set of transmission pricing rules should encourage efficient operation of, and investment in, the electrical system [1], but this is not sufficient to define a unique set of rules.

In general, there are two main classes of transmission pricing: those based around the differences in marginal prices of generation separated by a set of transmission facilities; and the others based on the actual costs of investing in and operating those same transmission facilities. The advantages and drawbacks of these two classes of pricing methodology in the key areas of economic efficiency, price signals to

Manuscript received September 30, 2006. This work was supported by the UK Government Engineering and Physical Sciences Research Council (EPSRC) as part of the SuperGen FutureNet Consortium, grant number GR/S28082/01.

Richard Green is Director of the Institute for Energy Research and Policy, 90 Vincent Drive, University of Birmingham, Birmingham B15 2TT, United Kingdom (Tel: +44 121415 8216, Fax: + 44121414 7377, e-mail r.j.green@bham.ac.uk).

Ian Elders and Graham Ault are with the Institute for Energy and Environment at the University of Strathclyde, Glasgow, G1 1XW, United Kingdom (e-mail: i.elders@eee.strath.ac.uk and g.ault@eee.strath.ac.uk). transmission network users, fairness, stability and revenue reconciliation are dealt with extensively in the literature (see [2] for a thorough overview of the various principles, benefits and potential shortcomings of different transmission pricing approaches). If transmission prices equal marginal costs, then system users who take these prices as given should act in a way that maximizes welfare (e.g. minimizes the total costs of meeting a fixed demand). This should lead to economic efficiency in both operating and investment decisions. The problem is that prices equal to marginal costs will typically only recover a small proportion of the total cost of the transmission system [3], and so additional charges will be needed.

The ICRP methodology described and applied in this paper [4] falls into the latter category of transmission cost based methods also knows as transmission cost allocation (TCA). This class of pricing methodologies starts from the baseline principle of allocating the full costs of all transmission facilities and therefore do not suffer from the revenue reconciliation problem of generation marginal price methods. TCA approaches in turn are subdivided into those based on a flat rate and those based on power flows (see [5] for a brief description of some methods and the key differences). Among the power flow based methods, there is diversity in the approaches used to allocate the use of transmission facilities (i.e. power flows) to generation and demand users of those facilities. The proportional sharing principle (PSP) [6] allocates power flows to generation and demand users based on injections into branches at each node in the system but are sensitive to minor changes in generating unit market positions. Methods based on generation shift distribution factors (DF) [7] have been shown to be sensitive to the choice of slack bus. More recently proposed approaches for TCA such as Equivalent Bilateral Exchanges (EBE) [5,8] overcome the noted drawbacks of PSP and DF methods. The ICRP method presented in this paper has none of these sensitivities and the relative merits of the approach are outlined in section II.

The problem is that the choice between alternative rules can lead to large transfers of shares of costs between users of the transmission system, and that many of these users are well aware of this. Once a rule has been adopted, changing it is likely to be politically difficult, and too much instability can discourage investment. Predicting the long-term consequences of a given pricing rule can help determine whether future changes might be necessary. 
In this paper, we apply the transmission pricing methodology currently used by National Grid - the transmission system operator in Great Britain (GB) - to four scenarios for the electricity industry in GB in 2020, and assess the resulting transmission charges. The scenarios [9] have been developed as part of the SuperGen Future Network Technologies ('FutureNet') research consortium's activities to show possible evolutions of the power sector (and country) over the next fifteen years, as intermediate stages in the development of scenarios for the year 2050 [10].

National Grid's current methodology, known as Investment Cost-Related Pricing (ICRP) sets annual transmission charges for generation capacity and for consumer demand, based on system conditions at the time of peak demand. The charges are based on the cost of building the network to meet the incremental flows stemming from additional generation (or demand) at each location. The transmission owners' remaining revenue requirements are effectively collected via uniform charges on generation and on demand, the approach often known as postage stamp pricing. Other transmission charging methodologies include nodal congestion pricing, when users must pay for their incremental impact on congested links at all times of the year, and locational charges for losses, which have so far been considered but never introduced in Great Britain. These charges can capture the short-run marginal cost of transmission, whereas ICRP attempts to reflect its long-run marginal cost.

Our motivations for this work are to illustrate a charging method that may not be well known internationally, and to explore the sensitivity of charges to plausible system developments. Generation developers need reassurance that their charges will not alter to the extent that projects become uneconomic in response to future developments. We will show that most transmission charges are not sensitive to differences between the scenarios we consider, which should provide some reassurance given the breadth of possible generation and demand outcomes that the scenarios cover. Finally, the specific predictions in the paper provide information for GB policy-makers on the future evolution of transmission charges.

In section II, we outline the ICRP system, and our methodology for calculating transmission revenues in 2020. Section III describes the key features of the FutureNet scenarios. Section IV applies the ICRP rule to the four scenarios, and Section V discusses the results. Section VI concludes. Our aim is to illustrate how sensitive the charges produced by this methodology are to changes in system conditions, rather than to compare alternative pricing methodologies.

\section{GB Use Of SyStem CHARging MEthodology: INVESTMENT COST RELATED PRICING (ICRP)}

As already stated, the ICRP methodology aims to collect the full, regulated, cost of the transmission system from its users, with regional differentials that are based on the differences between the long-run marginal cost of providing transmission to users in different areas.

The ICRP methodology was developed for introduction by National Grid in 1993 and subsequently updated in 2004 to include a full DC load flow model of the high voltage transmission system. A full description of the methodology is given in [4]. This paper explores the application of this pricing mechanism and its sensitivities to future generation, demand and network developments. The scope of the pricing mechanism covers all the lines defined as "transmission": 132 $\mathrm{kV}$ in Scotland, and $275 \mathrm{kV}$ and $400 \mathrm{kV}$ throughout Great Britain. The grid is modeled at the system peak, using the weather-adjusted Average Cold Spell demands, and scaling generation capacity so that it exactly matches demand. For each node in turn, the model calculates the incremental flows on each line in the system that would arise from a 1 MW increase in generation or in demand, offset by a reduction at the swing bus (Thorpe Marsh in Yorkshire). As discussed below, the choice of swing bus will not affect the final tariff. These flows are added up across the country, having been converted into equivalent MW-km, scaling up the length of lines that are at voltages below $400 \mathrm{kV}$, or are underground, to reflect their higher cost per unit of capacity. Denoting the incremental flow from an increase in generation at node $i$ as $f_{i}$, we have:

$$
f_{i}=\sum_{k} \phi_{i k} l_{k} r_{k}
$$

where $\phi_{i k}$ is the power transfer distribution factor from the DC load flow equations that gives the incremental flow on line $k$ from a $1 \mathrm{MW}$ increase in generation at node $i, l_{k}$ is the length of line $\mathrm{k}$, and $r_{k}$ gives the relative cost of different types of lines. It equals 1.0 for a $400 \mathrm{kV}$ overhead line, is slightly higher for $275 \mathrm{kV}$ and $132 \mathrm{kV}$ lines, and far higher for underground cables.

To obtain a tariff, the figures in MW-km per MW of incremental demand have to be converted to figures in $\mathrm{E} / \mathrm{kW}$ of capacity. This is done by multiplying them by the annualized cost of transmission capacity per MW-km. National Grid starts with the estimated direct annual cost of a MW of capacity on a $400 \mathrm{kV}$ line, which it calls the expansion constant, equal to $£ 10.07$ per MW-km in 2006/7. Transmission companies in Great Britain have to build their systems to an N-2 security standard, however, and if flows rose by $1 \mathrm{GW}$, then adding only $1 \mathrm{GW}$ of capacity would probably breach this rule. National Grid reflects this electrical reality by scaling up its expansion constant by the "locational security factor", currently 1.80 . The practical impact of this choice is to raise the price differentials between nodes, compared to a system without this security factor. We would thus have a basic tariff $\tau_{i}$ given by:

$$
\tau_{i}=f_{i} \times 10.07 \times 1.80=\sum_{l} \phi_{i k} l_{k} r_{k} \times 10.07 \times 1.80 \equiv \sum_{k} \phi_{i k} c_{k}
$$

where $c_{k}$ is defined as the annual cost of line $k$. Lines that National Grid deems to have significant spare capacity are 
assigned a value of $c_{k}$ that is reduced by $25 \%$.

It is highly unlikely that this basic tariff would recover the correct amount of revenue for the transmission companies, however, and it is adjusted to do so. Ofgem, the GB power sector regulator, has decreed that generators should collectively pay $27 \%$ of the companies' revenue requirements, and consumers $73 \%$. National Grid therefore raises (or reduces) all the initial tariffs by a uniform amount that will allow it to meet this requirement. Denoting the revenue to be recovered from generators by $R_{G}$, and the generation at node $i$ by $g_{i}$, we have a scaled tariff equal to:

$$
t_{i}=\sum_{k} \phi_{i k} c_{k}+\frac{1}{\sum_{i} g_{i}}\left(R_{G}-\sum_{i} g_{i} \sum_{k} \phi_{i k} c_{k}\right)
$$

We can use equation (3) to show that the choice of swing bus is irrelevant to these transport tariffs. Given the properties of the DC Load Flow model, if we choose an alternative swing bus, $s$, we have a new set of power transfer distribution factors $\phi_{i k}^{\prime}$, where $\phi_{i k}^{\prime}=\phi_{i k}-\phi_{s k}$. That is, the incremental flows from any node to the new swing bus are given by the incremental flows from that node to the old swing bus, plus the flow from the old swing bus to the new one, or (equivalently) less the flow from the new swing bus to the old one. Given this relationship, we can calculate the scaled tariff resulting from the new swing bus, $t_{i}^{\prime}$, as:

$$
\begin{aligned}
t_{i}^{\prime} & =\sum_{k} \phi_{i k}^{\prime} c_{k}+\frac{1}{\sum_{i} g_{i}}\left(R_{G}-\sum_{i} g_{i} \sum_{k} \phi_{i k}^{\prime} c_{k}\right) \\
& =\sum_{k}\left(\phi_{i k}-\phi_{s k}\right) c_{k}+\frac{1}{\sum_{i} g_{i}}\left(R_{G}-\sum_{i} g_{i} \sum_{k}\left(\phi_{i k}-\phi_{s k}\right) c_{k}\right) \\
& =\sum_{k} \phi_{i k} c_{k}+\frac{1}{\sum_{i} g_{i}}\left(R_{G}-\sum_{i} g_{i} \sum_{k} \phi_{i k} c_{k}\right)=t_{i}
\end{aligned}
$$

The choice of swing bus is thus irrelevant for the final scaled tariff. In practice, the calculations used by National Grid involve some additional stages, but they do not affect this result. We verified this result by running scenarios with the swing bus set at a different location, and found that the prices are completely invariant to the choice.

While the choice of a slack bus has been shown not to affect the differentials in prices between different areas, there will normally be one bus with a zero price for generation, and one (normally different) with a zero price for demand. The choice of the proportion of revenues to be raised from generation and demand customers (73:27 respectively, as noted above) does affect the location of these 'implied' slack buses. Altering the 73:27 split will alter the locations within the system that return a zero charge from the methodology. In addition, it should be noted that the generation to demand revenue split affects the absolute level of prices paid by customers in different geographical locations while not affecting the relative differences in prices between the zones. The relative price differentials between zones are affected by the power flows (a function of generation and demand magnitude and geographical disposition) and also by the annualized cost of transmission capacity per MW-km and the security factor as described above. These latter two factors are set by the transmission system operator but an assessment of their impact is beyond this paper.

The most important extra step in National Grid's tariff calculations is that while the incremental flows are calculated for each node on the system, transmission charges are set for 14 demand zones (the areas of the fourteen GB distribution network operators) and a potentially variable number of generation zones (currently 21). The generation zones are chosen by grouping nodes with similar incremental flows that are electrically and geographically close together. These zones are shown in Fig. 1.

The initial transport tariff for demand in a zone uses the load-weighted average of the incremental flows from each node, converted from MW-km to $£ / k W$ when they are multiplied by the expansion constant and the locational security factor. Similarly, the initial transport tariff for generation is calculated from the capacity-weighted average of the incremental flows at the generation nodes. The corrections to get the desired revenue recovery are then made to these averaged tariffs.
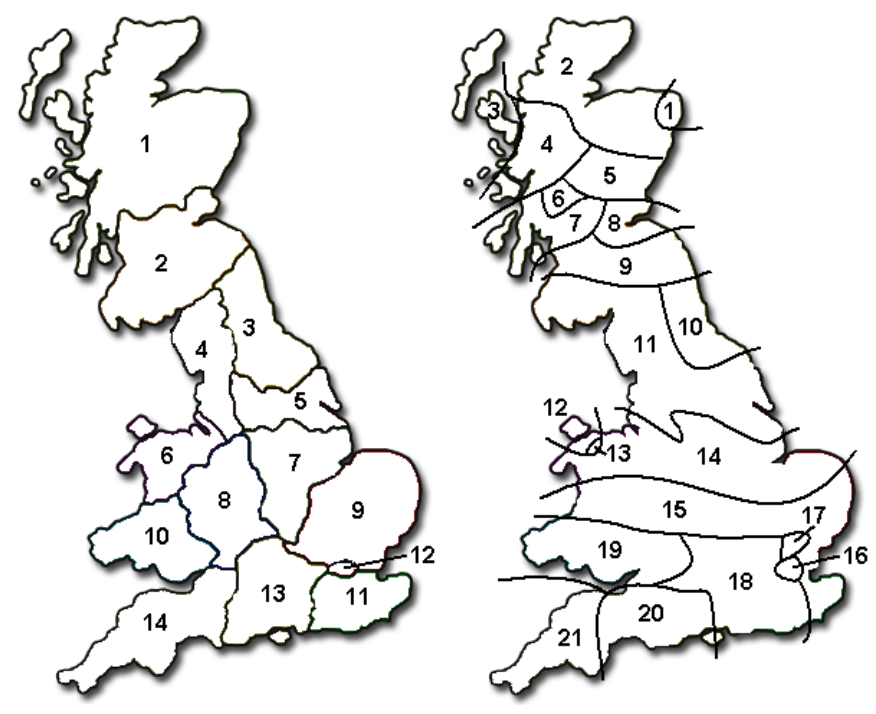

Fig. 1: Demand (left) and generation (right) zones in 2006

In a final stage, any negative demand tariff is raised to zero. The Transmission Use of System charges are applied to consumption in three peak half-hours, and can dwarf the energy price in those half-hours. National Grid argues that it would be inappropriate to give users the incentive to increase peak consumption that a negative transmission charge might imply, and so eliminates any negative charges. The practical impact of this rule is actually low - we only obtained a 
negative demand tariff, before applying the rule, for one zone in one scenario. Generators in favorable locations do face negative capacity charges, which amount to a payment for the support that they provide to the grid. This payment is only received for the output actually supplied at the times of the system peak. This gives a strong incentive to be available at those times (when almost all available generators would be running, in any case), but is not counter-intuitive in the same way as paying consumers to raise their demand. The different treatment of demand may owe as much to politics as to economics, but we reiterate that its practical impact is small.

The ICRP methodology should be seen as a way of deciding how the costs of the transmission system are shared among users. It does not attempt to send short-run price signals for efficient operation, but to collect revenues in a manner that produces regional differentials that are aligned with differences between the long-run marginal costs of providing transmission for users in different parts of the interconnected system. All the charges for using the transmission system are collected by National Grid, and there are no bilateral arrangements for point-to-point transmission between generators and loads.

The methodology does contain some simplifications, made in the name of greater transparency (and this paper could only be written because National Grid makes its model freely available), but the calculated price differentials reflect cost differentials, and the methodology performs well against its objectives. National Grid's first ICRP tariffs ignored the actual power flows (now calculated using a DC Load Flow algorithm) effectively sending power along the shortest route in (adjusted) MW-km. This resulted in much lower price differentials and hence produced a rather inferior result (from the point of view of reflecting costs). Since even these lower price differentials were greater than users had been facing before the ICRP system was introduced, their low level may have been politically useful to National Grid.

\section{GB 2020 SCENARIOS}

Four scenarios for the GB power system in the year 2020 were developed under the SuperGen FutureNet collaborative research initiative. Full details of the scenarios are found in [9]. The scenarios address many of the key issues affecting the power system in GB and worldwide. Some of the key issues the scenarios deal with include:

- Growth and development of renewable generation

- Demand growth in a post-industrial and service oriented economy

- Implementation of advanced demand side and efficiency measures

- Retirement and replacement of the conventional generation fleet

- Decline then possible growth in nuclear generation

Different combinations of these issues and trends (and many other driving forces in the power sector) are collated into four plausible scenarios for 2020 that have the following titles and summaries:

- 'Continuing Prosperity' (CP): This scenario envisions a future in which buoyant economic growth is supported by strong research and development investment in electricity network and generation technology. These factors result in an electricity industry of increasing technical sophistication, in which long-term growth in demand for energy services is addressed through a combination of continuing investment in network infrastructure and strong promotion of load management measures such as energy efficiency and demand-side participation.

- 'Environmental Awakening' (EA): This scenario considers a future in which the impact on the environment of the electricity industry, including generation, networks and end use, is a matter of increasingly important and popular concern. This awareness has its foundation in the heightened public awareness of climate change and the environment evident currently.

- 'Supportive Regulation' (SR): This scenario describes a future in which the government and regulatory authorities exert a gradually increasing influence over the development of the electricity industry. This development is brought about by increasing public concern over issues such as energy security and strategic planning issues associated with power generation and network infrastructure.

- 'Economic Concern' (EC): This scenario envisages a future in which the economy enters a period of moderate decline, perhaps as a result of significant fuel price increases or because of unfavorable conditions in the wider global economy. As a result, the availability of finance for investment in the electricity network and for research into generation and network technologies is restricted. Concern over the economy tends to replace environmental issues in the public consciousness; therefore pressure to achieve targets on emissions and thus deployment of renewables tends to reduce in this scenario.

The scenarios were developed with reference to other energy and power sector scenario activities (details of the associated work can be found in [9] and [10]) and are intended to provide plausible future conditions under which the power sector will exist. They have found wide use in the sector in GB.

The four scenarios produce different drivers for electricity demand, generation and power networks. The generation mix and demand in each of the scenarios are detailed in Table I: 
TABLE I

GENERATION TECHNOLOGY CAPACITY MIX AND SYSTEM PEAK DEMAND FOR EACH 2020 GB SCENARIO

\begin{tabular}{lcccc}
\hline \hline & \multicolumn{5}{c}{ Generation capacity per scenario } \\
Generation technology & \multicolumn{5}{c}{ (GW) } & EA & SR & EC \\
\hline Wind generation & 12 & 15 & 10 & 8 \\
Marine generation & 2 & 2.5 & 2 & 0 \\
Biomass & 7 & 9 & 8 & 7 \\
Hydro & 2 & 2 & 2 & 2 \\
Micro-generation & 3 & 6 & 0.2 & 0 \\
Nuclear & 8 & 7 & 13 & 8 \\
Large gas-fired units & 44 & 35 & 38 & 36 \\
Coal & 9 & 4.5 & 12 & 13 \\
Total Generation & $\mathbf{8 1}$ & $\mathbf{8 1}$ & $\mathbf{7 7 . 2}$ & $\mathbf{7 4}$ \\
Capacity & & & & \\
GB Peak Demand in 2020 & 66 & 60 & 63 & 60 \\
scenario & 60 & 60 & 60 & 60 \\
GB Peak Demand in 2006 & &
\end{tabular}

The ICRP zonal transmission pricing approach leads to sensitivities in prices arising from the geographical disposition of demand and generation. Analysis of these four scenarios, with the demand and generation changes therein, will illuminate theses pricing sensitivities to different generation and demand outcomes. The following section describes a series of studies using the National Grid ICRP pricing model adapted to reflect the changes in generation, demand and transmission network under each of the 2020 scenarios. This allows exploration of the effects of the different scenarios and additional sensitivity cases.

\section{Application of Charging Methodology to SCENARIOS}

To calculate the ICRP tariffs for the 2020 scenarios, we therefore needed the incremental flows in MW-km for each zone, and the overall level of transmission revenues that the three transmission owners would be allowed to receive.

Transmission revenues were calculated by rolling forward the price control calculations that Ofgem makes for the three GB transmission companies. For a five-year period, the regulator predicts the companies' cash spending (operating costs, investment in the network, and tax payments) and the change in the value of their transmission assets (investment less depreciation). A company's allowed revenue is equal to its cash spending over the period, less the change in the net present value of its assets. If a company is investing heavily, while depreciation is low, the value of its assets will rise. This offsets the investment spending when the transmission revenues for the current period are being decided, ensuring that transmission users pay for the assets over many years, and not all at once.

We assumed that the companies' controllable operating costs would grow at $1 \%$ a year, and that their non-controllable operating costs would be constant in real terms. We assumed that the base level of capital expenditure would rise by $3 \%$ a year for each company, and added the cost of any additional network investments that we included in our scenarios. We assumed that tax payments would fall by $10 \%$ a year, given the companies' rising investment levels (under the UK tax system, high investment allows companies to reduce their tax payments). All of these trends are in line with those shown in Ofgem's initial calculations for the 2007/8 - 2011/12 transmission price control [11].

We assumed that the revenue required over a five-year period would be recovered evenly across the five years. Our chosen year, 2020, is towards the middle of a price control period, which reduces the impact of this assumption on the prices in that year. The price control calculations include revenues that will not be recovered through the ICRP charges, such as charges for connecting to the network. We assumed that the revenue to be recovered from ICRP charges would be a constant proportion of the revenue required from the price control calculations throughout the period. This gave us a predicted revenue requirement, from ICRP charges, of $£ 1175$ million, in 2004/5 prices, on which the transmission prices in this paper are based. This revenue is recovered from all users of the transmission system in Great Britain, and passed on to the three transmission owners in line with their regulated revenue requirements.

\section{A. Modifications to ICRP for year 2020}

Our starting points for the application of the charging methodology to the scenarios described above were the current versions of National Grid's publicly available transmission charging model, and of their Seven Year Statement (SYS) document [12]. The SYS describes the changes to the British transmission network proposed for each year to 2012, and lists new generation developments that have entered into contracts to connect to the transmission system over that period. Since the British regulatory regime does not require generators to provide long-term advance notice of permanent or temporary closure of power stations, the SYS does not list such changes.

The 2006 charging model was modified by updating the transmission network transport model to reflect planned changes to 2012, and adding new generators contracted to connect up to that date. The model was then projected forward to 2020 by retiring existing gas turbine and steam (i.e. coal, oil, gas and nuclear) plant based on a nominal 40-year lifetime. No further modifications to the network topology were made other than those planned to 2012 in the SYS.

This resulted in a "baseline" 2020 model onto which the demand and generation developments outlined in each scenario could be applied.

\section{B. Modeling of 2020 scenarios}

Each of the scenarios described above calls for a particular capacity of the generation technology types as listed in Table I. In each case this capacity will be made up of a mixture of large, transmission connected developments, which are subject to the transmission charging regime, and smaller developments 
embedded within local distribution networks, which we assume do not pay transmission charges, and which effectively reduce the demand supplied by the transmission system. The proportion of large and small generation is assigned for each generation type within an individual scenario.

Furthermore, large generators in each scenario will be a mixture of new capacity built between 2012 and 2020 and existing capacity, some of which may be life extended beyond the initially-assumed 40-year lifespan. For each scenario and type of generation, an assessment is made of the willingness of stakeholders to invest in new plant for economic or environmental benefits in preference to extending the lives of old power stations. Resulting plant lifetimes varied between 40 and 45 years. However, we assumed that hydro-electric stations, some of which are already over 50 years old, would be life-extended indefinitely.

Generating units were generally retired in chronological order of their commissioning date, but as complete power stations rather than individual units, since owners would be unlikely to wish to incur the overhead costs of a complete power station to support a single unit for the last one or two years of its notional life. New gas-turbine and coal stations were located at the sites of closed plants in the model; in each scenario the required volume of new coal generation was concentrated into two or three large stations at suitable locations for access to local or imported coal supplies. Additional gas turbine capacity was then distributed among the remainder of available sites in proportion to the capacity of the retired plant. New nuclear generators, where required by a scenario, were placed at existing nuclear sites.

The level of demand at each node in 2020 was modeled by uniformly scaling the 2006 demand by the factor required in each scenario. The level of embedded generation within each distribution network operator's (DNO) area varies according to the scenarios and the capacity is uniformly distributed across the demand-carrying nodes within each DNO area. The full rated capacity of the embedded generation is subtracted from the demand at each node. In some cases, this results in net export from the distribution system into the transmission system, which is also (although to a lesser extent) a feature of the model published by National Grid.

The result of this process is a model approximating the likely distribution of generating capacity and demand in 2020 under each of the scenarios, which we go on to use to calculate the level of charges payable by electricity generators and retailers for use of the transmission system.

\section{RESULTS}

\section{A. Generation}

Table II, Fig. 4 and Fig. 5 show our predicted generation use of system charges, for the 21 generation zones currently in use. Using today's zones allows us to make a clearer comparison with the present-day charges, but it is possible that the generation zones might change over this period. National Grid groups nodes with similar charges into generation zones, and as power flows change, new groupings might become appropriate [13]. We discuss the implications of this below.

TABLE II

GENERATION TRANSMISSION USE OF SYSTEM TARIFFS FOR BASE CASES AND 2020 SCENARIOS (£/KW/YEAR)

\begin{tabular}{|c|c|c|c|c|c|c|}
\hline $\begin{array}{c}\text { Generation } \\
\text { Zone }\end{array}$ & 2006 & $\begin{array}{l}\text { Base } \\
2020\end{array}$ & $\begin{array}{c}\text { CP } \\
2020\end{array}$ & $\begin{array}{c}\text { EA } \\
2020\end{array}$ & $\begin{array}{c}\text { SR } \\
2020\end{array}$ & $\begin{array}{c}\text { EC } \\
2020\end{array}$ \\
\hline 1 & 18.4 & 19.3 & 17.2 & 18.4 & 17.7 & 18.9 \\
\hline 2 & 20.5 & 21.9 & 21.5 & 22.2 & 21.8 & 21.7 \\
\hline 3 & 13.3 & 24.1 & 23.4 & 24.0 & 23.4 & 24.2 \\
\hline 4 & 18.6 & 19.5 & 18.9 & 19.5 & 18.9 & 19.7 \\
\hline 5 & 15.4 & 18.0 & 16.9 & 17.6 & 16.9 & 17.9 \\
\hline 6 & 4.9 & 7.8 & 6.6 & 7.9 & 7.3 & 8.1 \\
\hline 7 & 13.5 & 19.3 & 18.1 & 19.0 & 18.5 & 19.2 \\
\hline 8 & 13.1 & 16.7 & 13.5 & 15.7 & 13.6 & 14.4 \\
\hline 9 & 12.1 & 11.1 & 10.0 & 10.8 & 10.8 & 10.9 \\
\hline 10 & 8.9 & 7.8 & 6.4 & 6.8 & 6.1 & 6.9 \\
\hline 11 & 5.6 & 5.3 & 3.7 & 4.4 & 3.8 & 4.5 \\
\hline 12 & 6.3 & 7.8 & 6.6 & 5.0 & 4.8 & 8.1 \\
\hline 13 & 8.9 & 8.7 & 7.5 & 8.3 & 8.1 & 8.6 \\
\hline 14 & 3.8 & 3.0 & 1.3 & 1.7 & 1.2 & 2.0 \\
\hline 15 & 1.2 & 0.3 & -1.4 & -2.6 & -3.2 & -2.1 \\
\hline 16 & -5.5 & -6.7 & -15.0 & -8.2 & -8.6 & -7.9 \\
\hline 17 & 0.4 & -0.6 & -2.4 & -2.6 & -3.2 & -2.3 \\
\hline 18 & -0.5 & -1.6 & -2.3 & -3.1 & -2.9 & -2.8 \\
\hline 19 & -2.7 & 4.1 & 3.1 & 3.1 & 3.1 & 3.2 \\
\hline 20 & -5.1 & -2.7 & -1.6 & -4.3 & -1.4 & -5.0 \\
\hline 21 & -9.2 & -1.3 & -0.7 & -2.9 & -0.6 & -3.8 \\
\hline
\end{tabular}

Fig. 2 shows how the generation tariffs vary across the country. In general, the current pattern of generation charges in which the tariffs decreases from north to south (generally leftto-right in the figure 2) is maintained. Tariffs rise in zones which see an increase in their net exports of electricity (generally speaking). This mostly affects northern zones (e.g. zones 3 and 6 are substantially higher for the 2020 cases than the 2006 case), but an increase in renewable generation in South Wales and the South West leads to an increase in these tariffs as well (zones 19 and 21). Since the total revenue requirement is hardly changed from 2006, other zones experience offsetting reductions in their tariffs. In general the charges change by a modest amount in most zones (as shown by the closeness of data points on the graphs) but the more significant generation tariff changes are in the order of 5-10 $\mathrm{E} / \mathrm{kW}$ at which level the economics of generation in those zones could be materially affected. Where the data points for the scenarios overly the 2006 tariff line there is effectively good stability in transmission use of system prices.

Fig. 3 shows some of the generation tariffs in a form which allows for easier comparison between years and scenarios. There is a particularly sharp increase in the tariff in zone 3 between 2006 and 2020. This is a zone with few network nodes which is remote from the main transmission system, and which sees a significant increase in renewable generation in all of the scenarios. As a result, the zone becomes a net exporter rather than importer of electricity; further generation in this 
zone would thus increase rather than reduce flow through the long connection to the main grid, resulting in a large increase in the tariff between 2006 and 2020.

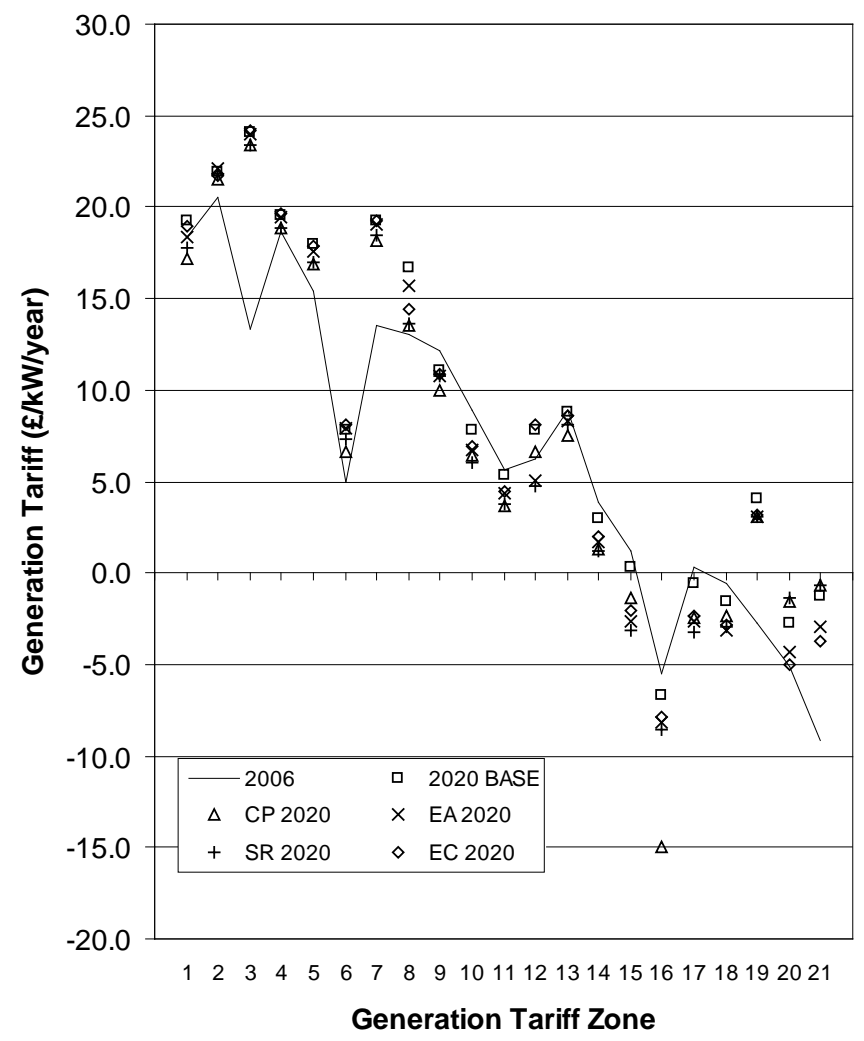

Fig. 2 : Generation Transmission Use of System Tariffs for each zone and scenario

There is also a significant rise in the tariff in zone 7 (Central Highlands) which results from the combination of increased renewable generation and the introduction of an underwater cable across the Clyde estuary, linking this hitherto remote zone more closely to the main cities of central Scotland. Much of the renewable output flows through these cables, which have a high cost per unit of capacity. The ICRP model scales up the length of the cables by a factor of more than 20 when calculating the MW-km of investment required (after power flows are computed), resulting in increased generation charges in this zone.

It is also notable that the significant negative tariffs in the south-west (zones 20 and 21) are reduced in nearly all of the scenarios as new renewable generation becomes available in these areas. However, the tariffs in these zones remain negative; signaling to potential developers that new generation in these areas would be beneficial in reducing overall network flow.

Power flows into zone 16 (Central London) rise, with increasing demand but little or no local generation, and the generation tariff becomes the most negative in the country. While this might normally provide an incentive to locate in the area, the difficulty of gaining local planning permission is likely to restrict this. We note, however, that this zone sees the greatest variation in charges between scenarios reflecting different demand trajectories for different scenarios.

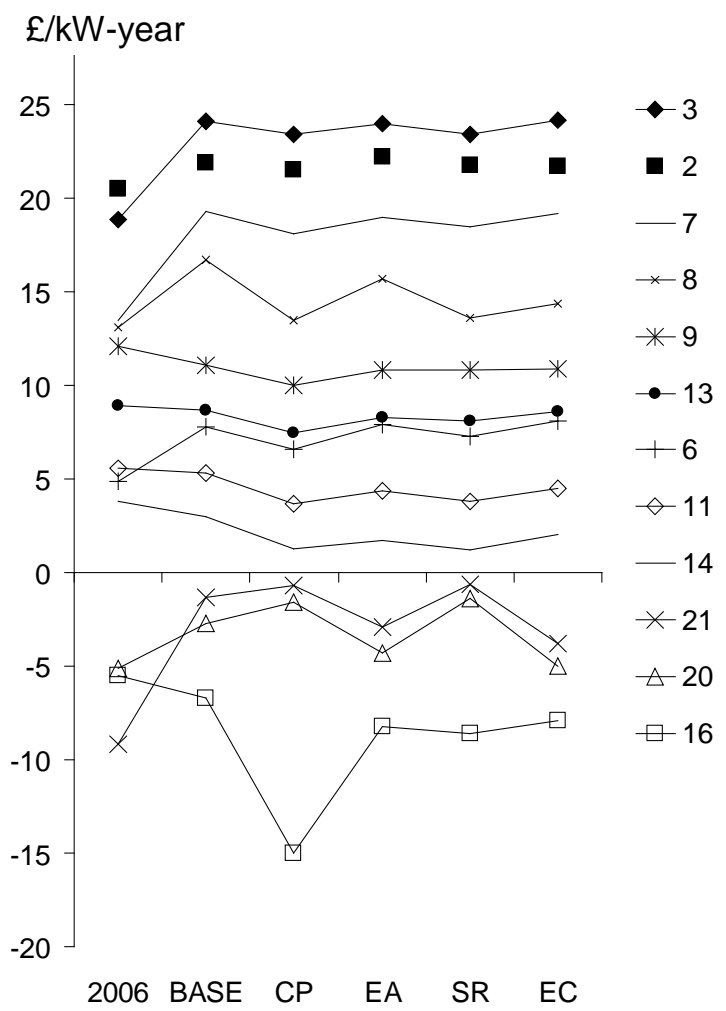

Fig. 3 : Generation Transmission Use of System Tariffs for selected zones base cases and 2020 scenarios (£/kW/year)

\section{B. Demand}

Table III, Fig. 4 and Fig. 5 show our predicted demand use of system charges, for the areas of the 14 distribution network operators.

TABLE III

DEMAND TRANSMISSION USE OF SYSTEM TARIFFS FOR BASE CASES AND 2020 SCENARIOS (£/KW/YEAR)

\begin{tabular}{ccccccc}
\hline $\begin{array}{l}\text { Demand } \\
\text { Zone }\end{array}$ & $\mathbf{2 0 0 6}$ & $\begin{array}{c}\text { Base } \\
\mathbf{2 0 2 0}\end{array}$ & $\begin{array}{c}\mathbf{C P} \\
\mathbf{2 0 2 0}\end{array}$ & $\begin{array}{c}\text { EA } \\
\mathbf{2 0 2 0}\end{array}$ & $\begin{array}{c}\text { SR } \\
\mathbf{2 0 2 0}\end{array}$ & $\begin{array}{c}\text { EC } \\
\mathbf{2 0 2 0}\end{array}$ \\
\hline 1 & 0.5 & 0.0 & 4.2 & 0.0 & 11.1 & 2.0 \\
2 & 5.5 & 4.5 & 5.6 & 7.4 & 5.4 & 5.8 \\
3 & 8.5 & 9.4 & 10.5 & 12.6 & 10.7 & 11.0 \\
4 & 12.0 & 12.7 & 14.1 & 15.6 & 13.7 & 14.0 \\
5 & 12.0 & 13.3 & 14.5 & 16.6 & 14.8 & 15.0 \\
6 & 12.2 & 13.1 & 14.1 & 15.7 & 13.6 & 14.0 \\
7 & 14.5 & 15.6 & 17.3 & 19.3 & 17.3 & 17.7 \\
8 & 16.1 & 16.0 & 17.1 & 19.1 & 16.8 & 17.5 \\
9 & 15.1 & 16.6 & 18.2 & 21.2 & 19.3 & 19.5 \\
10 & 19.7 & 13.3 & 13.7 & 15.1 & 18.7 & 14.8 \\
11 & 17.9 & 19.2 & 20.0 & 24.3 & 22.5 & 22.5 \\
12 & 19.8 & 21.2 & 23.4 & 27.6 & 25.6 & 25.9 \\
13 & 19.4 & 19.8 & 20.5 & 23.3 & 20.2 & 22.0 \\
14 & 22.2 & 17.8 & 17.2 & 21.0 & 17.2 & 20.3 \\
\hline \hline
\end{tabular}




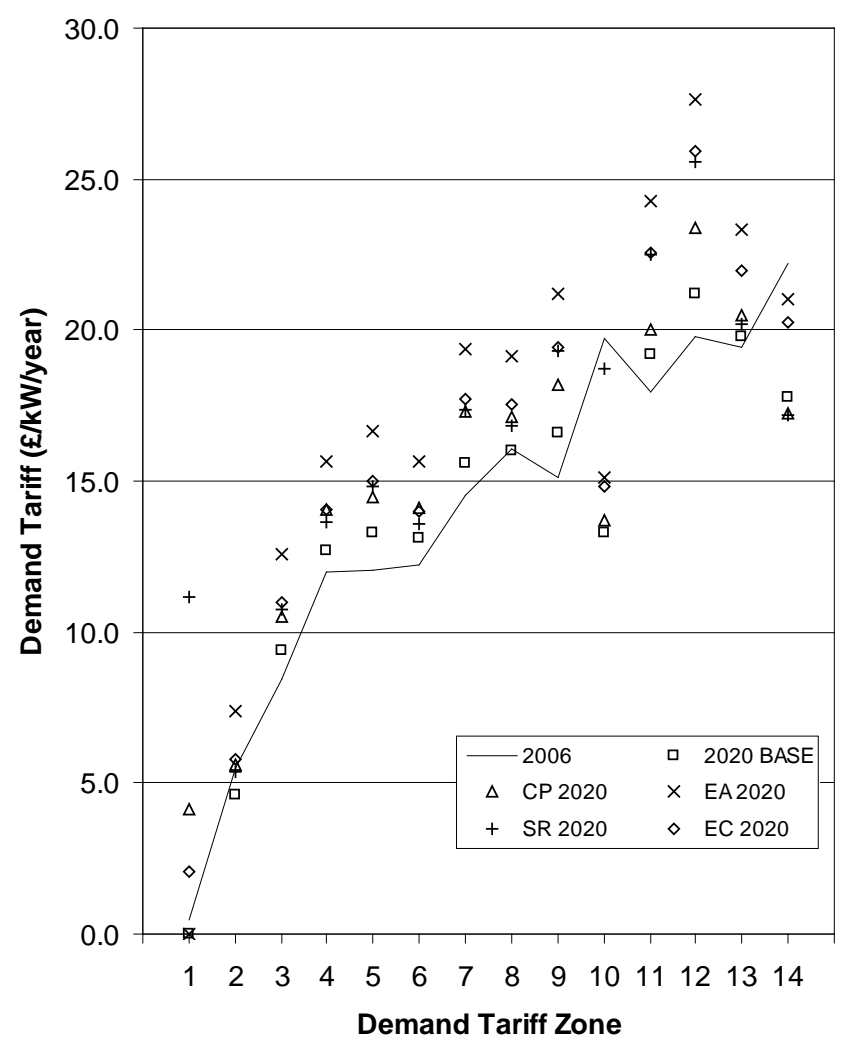

Fig. 4 : Demand Transmission Use of System Tariffs for each zone and scenario

Fig. 4 shows how the demand tariffs vary across the country. It can be seen that the general pattern in which demand tariffs increase from north to south continues. Tariffs are generally higher in 2020 than today, except in zones 10 and 14 (South Wales and South-west England). The effect over most of the country results from the displacement of coalfired generators in north and central England by renewable sources, particularly in Scotland. As a result, electricity is being transported further to meet demand in England. The degree to which charges increase depends on the extent to which renewables are exploited. For example, in zone 6 north Wales and the city of Liverpool - renewable generation increases strongly, leading to greater self-sufficiency and reduced import of electricity (although that which is imported travels further). In zones 10 and 14, the increase in renewable generation is sufficient to overturn the effect of increased transport distance and leads to a reduction in demand charges. This is the corollary to the increase in generation charges in these areas (generation zones 19-21) seen above.

Fig. 5 shows the demand charges for selected zones in a format which allows clearer comparisons between scenarios. While some zones see only modest differences between scenarios, the amount of variation is greater than for the generation charges.

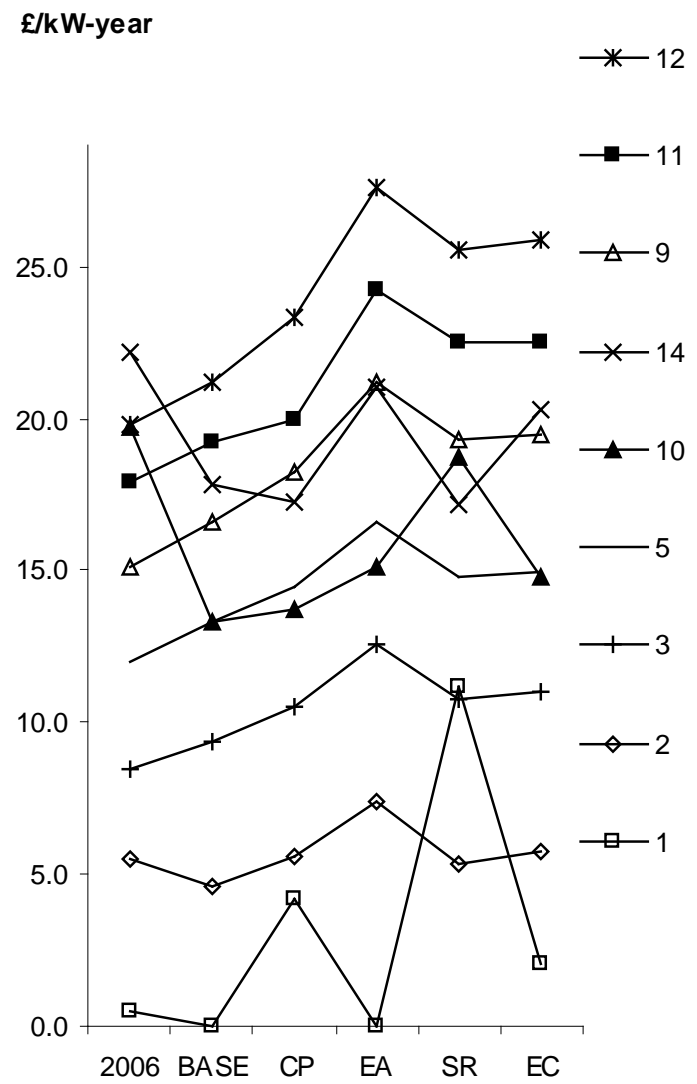

Fig. 5 : Demand Transmission Use of System Tariffs for selected zones - base cases and 2020 scenarios ( $£ / \mathrm{kW} /$ year).

The greatest variation is in the north of Scotland (zone 1), where the demand tariff, presently $£ 0.5 / \mathrm{kW}$-year, varies between $£ 11.1 / \mathrm{kW}$-year (in scenario SR) and zero (in scenario EA). Were it not for the need to avoid a negative demand tariff, this latter value would have been even lower. It is notable that this zone has a relatively low level of demand at present, which is further diluted in the scenarios by the connection of small-scale renewable generation embedded within the distribution network (for which there are significant opportunities in northern Scotland). As the installed capacity of embedded generation approaches and ultimately exceeds the total demand in this zone, large variations are experienced in the load-weightings used to average the nodal tariffs and produce a zonal tariff. Modifications to the tariff calculation method are likely to be required to eliminate this effect before embedded generation reaches such a significant level, in order to provide clarity in the likely future level of charges experienced by users of the transmission system.

It is arguable also that since some of this embedded generation will be making use of the transmission system to transport power to other nearby nodes in the same zone, it should therefore contribute to the funding of the transmission network through the use of system charging mechanism. Further research into how these issues could be fairly resolved appears to be required. 


\section{Zoning Issues}

National Grid has recently been required to produce forecasts of future ICRP tariffs, and has published its first two forecasts $[14,15]$. This was a license requirement to give information to system users on the likely evolution of their charges. National Grid forecasts the tariffs for five years into the future (which it describes as "long term") and so our results are not directly comparable. Nevertheless, some points of comparison can be made. In most cases, National Grid's charges change smoothly over time, and by relatively small amounts. Where there are large changes, they are in zones which have little generation or demand - our results have the same feature in the Central London generation zone (no. 16), for example.

One feature of the National Grid studies is that the generation zone boundaries are sometimes changed. In its first long-term forecast [14], the tariffs were based on 21 zones in 2005/6 and 2006/7, but 24 zones from 2007/8 onwards. No such changes were made in the second forecast [15], but the company is consulting on a possible re-zoning exercise [13]. This can have two impacts. First, moving nodes out of a zone can have an impact on the tariff across the remaining nodes, since it will be based on the average of a smaller set of numbers (the initial tariffs at those nodes). Second, and more important, the tariff at the nodes that are moved is likely to change significantly. This is inevitable, since the criterion for moving the nodes out of their former zone is that their initial tariff is now too dissimilar from their neighbors'.

In the context of our results, this raises an important point. In most cases, plausible changes in generation will have little impact on the charges for a given zone, which is a reassuring result for developers. Moving between existing zones, however, or into a completely new zone, can have a large impact on the charges faced by a generator. Such a movement is most likely to be required just after a new generator has been connected to the grid, and could lead to a sharp difference between the tariff assumed in the generator's plans and the tariff it has to pay. (This is not an issue for consumers, since their zone boundaries are fixed). While the DCLF model is a transparent tool for setting the initial nodal charges, National Grid inevitably, and sensibly, has discretion in how the nodes are grouped into generation zones. Further research on whether this discretion could cause unacceptable uncertainty for generation developers seems necessary.

\section{CONCLUSIONS}

The ICRP transmission use of system charging methodology (as currently used in GB) has been described and applied to scenarios for the GB power system in 2020. In general terms, the charges remain relatively stable across the period to 2020 and across the four scenarios. However, on close inspection it can be seen that in several cases, there will be large changes in tariff out to 2020. The reasons for these changes are the gradual change in generation and demand disposition over the period and across the four scenarios. However there are some significant issues in the ICRP methodology that may lead to more unfavorable outcomes for some system users. The effect of growing distribution-connected generation in low demand areas and the necessity for individual system nodes to be reallocated to zones periodically are two such deficiencies in the method. The study has provided insights into the scenarios themselves since the changes in use of system prices are not just an outcome of the scenarios but also a driver of the changes in demand and generation. These use of system tariffs must now be used to explore whether the generation and demand developments foreseen in the scenarios are realistic with tariffs at the levels presented in this paper.

A second strand of work is to compare the ICRP method with alternative ways of charging for transmission. The issues in the ICRP method revealed in this work would provide a focus for such a comparison. Charging for transmission services on a nodal basis would avoid large changes when a node is reassigned between zones, for example, but the nodal charges might be more volatile than zonal fees. One particular concern in the GB context is that high transmission tariffs might discourage investment in renewable generation in Scotland. Reverting to the earlier charging method based on distance minimization rather than full DCLF might reduce transmission charges in Scotland, but an alternative would be to keep the ICRP method and find some other way to ensure renewable generation receives enough support. A proper analysis of this issue requires a study of investment decisions as well as of transmission charges, thus combining both strands of work suggested above.

\section{REFERENCES}

[1] R. J. Green, "Electricity transmission pricing - an international comparison” Utilities Policy vol. 6, pp. 177-184, Sep. 1997.

[2] D.S.Kirschen , G. Strbac, Fundamentals of Power System Economics, Chichester, UK: Wiley, 2004 (especially chapter 6)

[3] I.J. Perez-Arriaga, F.J.Rubio, J.F. Puerta, J.Arceluz and J. Marin, "Marginal Pricing of Transmission Services: An Analysis of Cost Recovery” IEEE Transactions on Power Systems, vol. 10, , pp 546-553, Feb. 1995.

[4] National Grid plc "The Statement of the Use of System Charging Methodology Effective from 1 April 2006”, April 2006

[5] F.D. Galiana, A.J. Conejo, and H.A. Gil, "Transmission network cost allocation based on equivalent bilateral exchanges”, IEEE Transactions on Power Systems, vol. 18, pp1425-1431, Nov. 2003.

[6] J. Bialek, "Topological generation and load distribution factors for supplement charge allocation in transmission open access", IEEE Transactions on Power Systems., vol. 12, pp. 1185-1193, Aug. 1997.

[7] W. Y. Ng, "Generalized generation distribution factors for power system security evaluations”, IEEE Trans. Power App. Syst., vol. PAS-100, pp. 1001-1005, Mar. 1981.

[8] H.A. Gil, F.D. Galiana and A.J. Conejo, "Multiarea Transmission Network Cost Allocation”, IEEE Transactions on Power Systems, vol. 20, pp1293-1301, Aug. 2005.

[9] G.W. Ault, I.M. Elders, J.R. McDonald R. Tumilty, and G.M. Burt "Electricity Network Scenarios for 2020", SuperGen Future Network Technologies Consortium, Tech Rep. EPSRC/SGFNT/TR/2006-001, July 2006: http://www.supergennetworks.org.uk/publications/publications_softcopies/EPSRC-SGFNTTR-2006-001-2020-scenarios-report-July2006.pdf

[10] I.M. Elders, G.W. Ault et al "Electricity network scenarios for the United Kingdom in 2050" in Future Electricity Technologies and Systems, T. Jamasb, W.J. Nuttall, M.G. Pollitt, Eds, Cambridge, UK: Cambridge University Press, 2006, pp. 24-79. 
[11] Ofgem Transmission Price Control Reviews: Initial Proposals, ref 104/06. London; Office of Gas and Electricity Markets, June 2006: http://www.ofgem.gov.uk/Networks/Trans/PriceControls/TPCR4/Consu ItationDecisionsResponses/Documents1/14439-104-06AMEND.pdf

[12] National Grid plc, 2006 GB Seven Year Statement available online at: http://www.nationalgrid.com/uk/Electricity/SYS/.

[13] National Grid plc, 'Consultation document regarding the application of the Transmission Use of System charging methodology for determining the generation charging zones for the price control period beginning 2007/08', September 2006.

[14] National Grid plc, 'Information Paper: Condition 5 - Publication of Long-Term Tariffs', November 2005: http://www.nationalgrid.com/NR/rdonlyres/27BD50CD-BCA1-4594874B-DE18C35ACCB0/5269/Condition5LongTermTariffs.pdf

[15] National Grid plc, 'Information Paper: Condition 5 - Publication of Long-Term Tariffs', September : http://www.nationalgrid.com/NR/rdonlyres/E1C7183E-7C31-4C188A8F-309A87FB459C/10765/InformationPaperFINALv2.pdf

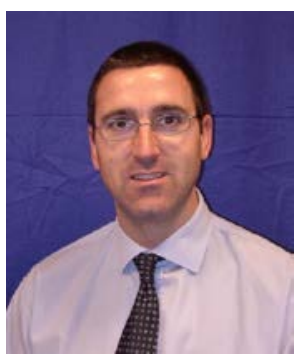

Graham Ault (M’1998) received his Bachelors in Electrical and Mechanical Engineering (1993) and $\mathrm{PhD}$ in Electrical Power Systems (2000) from the University of Strathclyde, Glasgow, UK.

Since 1996 has been researching in the field of power system planning and economics focusing on future power system architectures, distributed generation and utility asset management. He is currently a Senior Lecturer at Strathclyde.

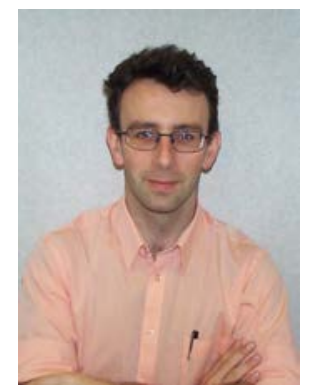

Ian Elders received his BEng degree in electronic and electrical engineering and $\mathrm{PhD}$ in electrical power engineering from the University of Strathclyde, Glasgow, UK in 1994 and 2002 respectively.

He is currently a Senior Research Fellow within the Institute of Energy and Environment at Strathclyde. He has previously undertaken research in collaboration with SW Electricity, National Grid and GE Harris Energy Control Systems.

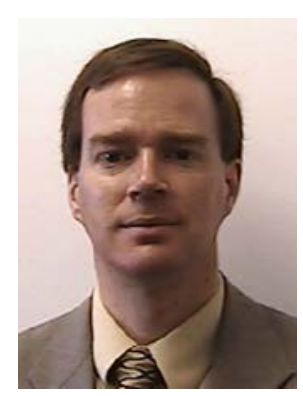

Richard Green received the degrees of BA (now $\mathrm{MA}$ ), M. Phil and $\mathrm{PhD}$ in economics, all from the University of Cambridge, UK, in 1988, 1989 and 1995 respectively.

He is Professor of Energy Economics at the University of Birmingham, UK, and Director of the Institute for Energy Research and Policy there. He was previously Professor of Economics at the University of Hull, and a Senior Research Officer at the University of Cambridge. He has held visiting positions at the World Bank, the University of California and MIT. His main research interests are in the economics and regulation of the electricity supply industry. 